\title{
The Right to a Fair Trial - A Tool for Self-Regulation
}

\author{
Order is not pressure which is imposed on society from without, but \\ an equilibrium which is set up from within. \\ ORTEGA Y GASSET
}

The analysis of the case-law on the applicability of Article 6(1) ECHR invites to the table a few conclusions about how the ECtHR has used this provision to enlarge the field of application of the ECHR and to strengthen its self-regulatory muscle.

A widely-shared misconception is that the ECtHR acts somewhat out of momentary caprice, opportunistically choosing when to enlarge its jurisdiction. Another misconception is that, when the ECtHR enlarges its jurisdiction, it acts unilaterally, almost in a despotic way. The analysis in this chapter however dispels these misunderstandings. First, the case-law that I have described above indicates that the ECtHR adopts a progressive approach to the interpretation of the rights enshrined in the ECHR. This approach involves a gradual "dragging" of disputes from non-applicability towards the applicability of Article 6(1) ECHR, and from non-justiciability towards justiciability.

Second, the ECtHR decides alone, but works collaboratively. The process of progressive enlargement of the Court's jurisdiction takes place with the cooperation offered by the member states, including their judiciary, the academic community and the zeitgeist. The Court's work is successful and its identity as a self-regulating tribunal is possible only because these elements are cooperative and cooperating. I provide a fuller description of these elements below.

\subsection{The Process Towards Justiciability}

The process of progressive "dragging" is accompanied by a simple, but consistent reasoning offered by the Court across the different fields of law analysed. Autonomous concepts are created at the meeting point between legal imagination and common sense. In addition, they are far from being scandalous or from provoking outcries from the member states or the general public. This 
wise use of language and the capacity to predict that member states will not use their limited resources to fight, for example, against the idea that petty offences are justiciable at the ECtHR, contributed to the creation of little visible opposition to the Court's strides towards enlarged justiciability.

The tension between the exercise of legal imagination and the consistent application of concepts is solved by the ECtHR by prioritizing the latter. Thus, despite the Court renewing its judges every 9 years, the criteria used for arguing in favour of the applicability of Article 6(1) ECHR to new fields of law have stayed the same. Consistency, thus, has been a key ingredient to the successful progressive enlargement of justiciability at the ECtHR.

Cross-fertilization has also been successfully employed by the ECtHR in its work of enlarging the applicability of Article 6(1) ECHR. The use of terms developed by the Court while working on other provisions of the Convention and of the terms developed during admissibility reasoning led to the harmonization of the case-law and to the strengthening of the concepts used. In Airey, the applicant could not get a divorce from her abusive husband. When rendering the judgement, the ECtHR highlighted the prominent place held in a democratic society by the right to a fair trial. Later, the ECtHR referred to this principle in Deweer to flesh out its reasoning concerning the applicability of Article 6(1) ECHR to economic offences. In Stafford, a case that concerned Article 5, the ECtHR found that it was necessary to look beyond appearances and the language used and to focus on the reality of the situation. The same precept has been employed by the ECtHR to reason the applicability of the right to a fair trial to prison disciplinary proceedings. Conversely, the notion of autonomous meaning that the Court has developed in Engel and Others in relation to the concept of "criminal charge" has become one of the most important concepts used by the ECtHR to interpret the Convention.

The case-law analysed above indicates that there is no way back from justiciability: once the ECtHR adopts a decision of applicability of Article 6(1) ECHR to a new field of law, there is very little chance that the Court will step back and decide that Article 6(1) ECHR is not applicable to that field of law. Exceptions to this rule exist, but, surprisingly, they seem to actually strengthen the system that produced them, instead of weakening it.

Thus, in the case of competition law proceedings, the ECtHR indicated in its early cases, Société Stenuit, Fortum Corporation and Lilly France s.A, that Article 6(1) ECHR was applicable and that competition law proceedings are justiciable under the ECHR. In ooo Neste St. Petersburg and Others, however, the ECtHR, with a majority voting, found that there was no "explicit conclusion" in the ECtHR's case-law about the applicability of Article 6(1) ECHR to competition law proceedings. This lack of "explicit conclusion" about the applicability of 
Article 6(1) ECHR has been remedied in Menarini, where the ECtHR unanimously explained at length that the right to a fair trial was applicable to competition law proceedings.

It thus appears that exceptions to the rule above do not shrink justiciability and do not weaken the system. Contrary to expectations, these exceptions actually strengthen the system of human rights protection enforced by the ECtHR because they feed the public debate outside the Court. This makes ECtHR more visible and enriches its image.

\subsection{The Role Played by the Academic Community}

Academia plays a role not only in systematizing the fields of law, but, more importantly, in their development as well..$^{1}$ In this sense, Arnull wrote that "important judgements are the subject of academic commentary which will be taken into account by the courts in the future" and that, especially in the civil law systems, "a critical academic consensus against a judgement may result in it being revisited by the courts". ${ }^{2}$ Furthermore, some authors speak about "an integrated community between judges and the academic world". ${ }^{3}$

Walker argued that judges, legal academics and professional commentators are "centrally implicated in the setting and pursuit of the juristic agenda" resulting from the failing of the Keynesian-Westphalian frame. Walker acknowledged that "in some respects the juristic agenda setters have remained too much in thrall to an older regulatory culture (...) to be particularly effective in the task of either diagnosis or treatment". However, he also highlighted that, because of a lacking meta-principle of authority, it is the theorists and commentators who become in fact the "key and unusually privileged symbolic analysts" of the Keynesian-Westphalian, global frame. ${ }^{4}$

1 Twining, William, Ward Farnsworth, Stefan Vogenauer and Fernando Tesón. "The Role of Academics in the Legal System." The Oxford Handbook of Legal Studies. Eds Mark Tushnet and Peter Cane. Oxford: Oxford University Press, 2005.

Vogenauer, Stefan. "An Empire of Light? II: Learning and Lawmaking in Germany Today." Oxford Journal of Legal Studies 26.4 (2006): pp. 627-663.

Braun, Alexandra. "Professors and Judges in Italy: It Takes Two to Tango." Oxford Journal of Legal Studies 26.4 (2006): pp. 665-681.

2 Arnull, op. cit., p. 427.

3 Bell, John, Sophie Boyron and Simon Whittaker. Principles of French Law. Oxford: Oxford University Press, 1998.

4 Walker, Neil. "Beyond Boundary Disputes and Basic Grids: Mapping the Global Disorder of Normative Orders." International Journal of Constitutional Law 6.3-4 (20o8), pp. 373-396, p. 395 . 
The academic community has played an important role in the process by which the ECtHR became a self-regulatory body expanding the applicability of Article 6(1) ECHR to new areas of law. As idea-shapers, the members of academic circles commented and discussed the case-law of the ECtHR, making it, thus, more visible. Also, more and more universities in Europe offer human rights law courses, summer schools and conferences that have heralded the kind of intellectual freedom and stimulation that is sensitive to new ideas and to a progressive view of the legal zeitgeist. The academic community is therefore an important source for the legal zeitgeist because of the cross-generational input that it constantly brings, its innate hunger for new ideas and its incubating nature. Also, the academic community receives and exchanges members with the state governments, with the judiciary and with the ECtHR. Indeed, most judges at the ECtHR come from academia or join academia at the end of their terms, ensuring a necessary migration and healthy recycling of ideas. ${ }^{5}$

\subsection{The Zeitgeist}

The post-wwiI period was a period of democratization in Europe, one that continued after the fall of the Berlin Wall and involved all the countries of the former Soviet bloc. Peace-building, democracy-strengthening, institutional re-imagination and community-building are all elements of the post-WWII Europe to which the ECtHR contributed. The unprecedented growth in importance and respect for international law and lawyers is another element of the zeitgeist. One can even argue that, in Europe, respect for the ECtHR's decisions became part of the zeitgeist.

To this, one can add elements of popular culture that involve a growing number of documentaries, movies and TV shows about trials that can influence the expectations that citizens have of the quality of the trials in which they are themselves involved.

\subsection{Cooperation with the ECtHR - Four Possible Models}

A decision of the ECtHR establishing that Article 6(1) ECHR is applicable to a dispute that was previously considered incompatible with this provision has

5 Arold Lorenz, Groussot and Petursson, op. cit., pp. 21-26. 
a few consequences for the member state concerned, for the other member states parties to the ECHR and for the ECtHR itself.

First of all, the member state against which the decision has been adopted must enforce this decision. When Article 6(1) ECHR becomes applicable to a dispute - for example, an employment dispute - it means that the defendant member state must ensure that the guarantees enshrined in Article 6(1) ECHR are respected during all subsequent domestic employment disputes. The ECtHR does not, however, prescribe how a dispute should be solved. This is left to the member state itself and can involve changes in the domestic procedural codes, amendments to other pieces of legislation or changes in domestic judicial practice.

At the same time, the other member states become concerned by the decision against the defendant member state because applicants from the other member states whose right to a fair trial has not been respected during employment disputes will be able to complain to the ECtHR. In order to prevent such disputes, the other member states are incentivized to ensure that their domestic employment laws are compatible with Article 6(1) ECHR.

Finally, when the ECtHR decides that employment disputes are justiciable, it can expect more applications concerning such disputes being lodged at its registry.

In other words, the applicability of Article 6(1) ECHR to new areas of law involves more work for all the member state parties to the ECHR and for the ECtHR itself. This has proved at times to be an unintended consequence for the ECtHR, one that became so serious that the Court had to question and revise its admissibility criteria. Having progressively enlarged its jurisdiction, the ECtHR started receiving an increased number of applications in the 199os. With no intention to increase its staff, the ECtHR found itself suffocated by the growing number of applications, most of which were dismissed as manifestly ill-founded.

At the same time, the ECtHR could not ignore these applications - the majority of which invoked violations of Article 6(1) ECHR - because they indicated a general dissatisfaction with the judicial processes offered by the member states. In other words, these applications can be interpreted as the member state not fully cooperating or engaging with the ECtHR.

Table 1 below indicates the importance of the cooperation offered to the ECtHR and highlights four possible models of cooperation. The categories tested for cooperation are the following: the defending member state (defending MS), that is the member state against whom the ECtHR has found a violation; the other member states (other Ms), that is all the other member states except the defending member state; and academic circles. 


$\begin{array}{lllll}\text { Cooperation } & \text { Defending } & \text { Other } & \text { Academic } & \text { Further } \\ \text { Model } & \text { MS } & \text { MS } & \text { Circles } & \begin{array}{l}\text { Applications } \\ \text { to ECtHR }\end{array}\end{array}$

\begin{tabular}{|c|c|c|c|c|c|}
\hline $\begin{array}{l}\text { Full } \\
\text { Cooperation }\end{array}$ & + & + & + & $\begin{array}{l}\text { Gradually } \\
\text { ceasing }\end{array}$ & Strengthened \\
\hline $\begin{array}{l}\text { Partial } \\
\text { Cooperation }\end{array}$ & + & - & $+1-$ & $\begin{array}{l}\text { Originate } \\
\text { from other } \\
\text { Ms s }\end{array}$ & Weakened \\
\hline $\begin{array}{l}\text { Partial } \\
\text { Cooperation }\end{array}$ & - & + & $+1-$ & $\begin{array}{l}\text { Originate } \\
\text { from the } \\
\text { defending MS }\end{array}$ & Strengthened \\
\hline $\begin{array}{l}\text { Non- } \\
\text { Cooperation }\end{array}$ & - & - & $+1-$ & $\begin{array}{l}\text { Originate } \\
\text { from } \\
\text { defending Ms } \\
\text { and the other } \\
\text { MS s }\end{array}$ & Weakened \\
\hline
\end{tabular}

When the member states or the academic circles cooperate, this is marked with an "+". When there is no cooperation, this is marked with "-".

Finally, Table 1 assesses the impact of the offered cooperation on the number of further applications received by the ECtHR and its capacity to self-regulate.

I argue that a few models of cooperation can be distinguished. These models assume that neither cooperation, nor refusal to cooperate can be permanent choices. The ECtHR's self-regulatory wisdom has fully integrated this assumption and worked around and with the member states that occasionally have been non-cooperative.

Model 1 - Full Cooperation: Both the defending Ms and the other ms s are being cooperative. They implement the ECtHR's decision by making legislative or practice changes. In addition, the academic circles cite and work with the ECtHR's case-law. As a result, both the legal principles enounced in the caselaw and the cooperative attitude of the Ms s and the academic circles become part of the zeitgeist. Since the issue that has generated the application at the ECtHR has been settled in the defending Ms and the other Ms s, this leads to no further applications being lodged with the ECtHR on the subject matter. If 
lodged, such applications would be rejected as manifestly ill-founded by a single judge at the ECtHR, that is, with a minimal use of resources. In time, such applications would cease to be lodged. Finally, the self-regulatory muscle of the ECtHR is strengthened by the received cooperative feedback.

Model 2 - Partial Cooperation: The defending MS cooperates, but other MS s refuse to integrate the decision of the ECtHR. In this case, the academic establishment from the other Ms s play a crucial role because they can either act as supporters or deniers of the ECtHR's case-law. In either case, by debating the issue, the problem raised at the ECtHR remains known and public. The fact that a legal dispute has been declared admissible at the ECtHR under Article 6(1) ECHR will mean that similar disputes from other MS s will be lodged at the ECtHR. This will allow the ECtHR the opportunity to repeat the principle formulated against the initial defending MS and to adapt it, depending on whether efficiency, stability or growth are to be satisfied first. Also, this will allow the ECtHR to reflect on and integrate into its newest cases the recent legal developments and the zeitgeist.

The self-regulation muscle of the ECtHR is weakened under this model because it sets a bad precedent of non-compliance. Also, if a large number of applications is received from the other Ms s, the ECtHR risks being overwhelmed. This was the case, for example, when the ECtHR started receiving applications concerning restitution of expropriated property originating from Romania. Even though the first cases on the issue of restitution of expropriated property that the ECtHR decided concerned Poland, the number of applications from Romania greatly increased the ECtHR's backlog.

The other, non-cooperating MS s will have, however, at least one incentive to embrace the solution proposed by the ECtHR against the defending Ms. If the issue settled against the defending MS is of concern to the other MS s - as was the case with the restitution of expropriated property or with the length of proceedings in many member states - it is likely that applications from the other MS s will eventually be lodged at the ECtHR. This creates additional work for the legal service of the government that must defend itself at the ECtHR and might attract unwanted public attention to certain domestic policies.

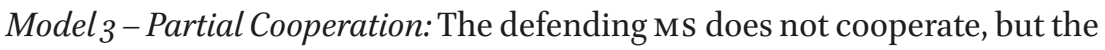
other MS s do. This model of partial cooperation is similar to the previous one. However, under this model, the possibility that the ECtHR's self-regulatory muscle will be weakened by an untenable number of applications is statistically lower when compared to the previous model of partial cooperation. Also, the academic circles from the cooperating MS s can play a crucial role influencing the academic circles in the non-cooperating MS. 
Model 4-Non-Cooperation: Neither the defending MS, nor the other MS s are cooperative, that is, all the members of the Council of Europe and the signatories of the ECHR refuse to enforce the decision of the ECtHR. Of all the models proposed in this chapter, it is in this situation that the academic circles might play a decisive role. They can step into the debate as defendants of the principles proposed by the ECtHR, thus preparing future generations of lawyers to adopt them, or they can dismiss the proposed principles.

Due to the member states' refusal to cooperate, the ECtHR risks receiving an increased number of applications from all the Ms s concerning the matter settled by the ECtHR against the defending MS. When the ECtHR is forced to act as a court of fourth instance, this weakens it internally because a large part of its resources will have to be allocated to dealing with the incoming cases. This situation also weakens the ECtHR externally because it shows the ECtHR as a tribunal whose decisions are not enforced and whose principles are heavily contested.

The first two parts of this book worked with the premises that first, the human rights system developed by the ECtHR became highly influential due to the design of the system, with the ECtHR at its centre as a self-regulating tribunal and that, second, the design of the human rights system developed by the ECtHR allowed the ECtHR to interpret the right to a fair trial in a way that has progressively enlarged the ECtHR's jurisdiction.

As it was proposed in Section 1.3. above, a self-regulating tribunal is one that displays two powers:

(1) It has competence to decide its own jurisdiction and

(2) It is able to have an impact on the flow and quality of incoming applications.

The ECtHR operates between coexisting but opposing needs - growth, efficiency and stability. The possibility of alternatively satisfying these requirements in order to ensure the continuation of the system is a landmark of selfregulation. Self-regulation is marked by the ability to choose the strength of the Court's intervention, of its influence on the zeitgeist. Sometimes, this is a forceful act of imposing an idea. Other times, it is about planting a seed; it is about the discrete inception of an idea whose time has not fully come.

The source of the ECtHR's self-regulation is the last paragraph of Article $3^{2}$ ECHR which empowers the Court to decide its own jurisdiction in case of doubt over this matter.

Chapter 6 argued that Article 6(1) ECHR has been the main engine for enlarging the ECtHR's jurisdiction and, therefore, for self-regulation. The 
case-law concerning the applicability of Article 6(1) ECHR indicates that the ECtHR used this provision to offer its supervisory role to disputes that have originally been considered as belonging to the realm of public law and, therefore, excluded from the applicability of Article 6(1) ECHR such as constitutional disputes, employment disputes, disciplinary disputes and competition law disputes, among others.

At the same time, Chapter 6 concluded that the progressive enlargement of the ECtHR's jurisdiction and of its self-regulatory powers was possible only because of the cooperation offered by the member states, including their judiciary and academic circles, and the zeitgeist. A cooperating Ms enforces the decisions of the ECtHR in a timely manner, by adapting the relevant legislation or judicial practice. A cooperating academic community follows the decisions of the ECtHR and includes its case-law in university curricula and conference agendas.

The analysis of the models of cooperation offered by the member states and by academic circles shows that four models of cooperation exist, ranging from full cooperation, beneficial both for the member states and for the ECtHR, to partial cooperation and non-cooperation which does not benefit any of the participants.

The work on the applicability of Article 6(1) ECHR is important for another reason. It indicates that the ECtHR has placed fair trial at the core of the erosion of public law in Europe. On the one hand, the growing importance of the state after the WWII has led to an increased regulation of life by the executive. On the other hand, both decriminalization and the development of administrative law in the member states of the Council of Europe has been accompanied by a tendency to ensure minimal fair trial guarantees in the new proceedings. The ECtHR has consistently defended due process as a democratic principle that must be ensured by the member states, irrespective of the name or formal nature of the chosen procedure.

I have placed great emphasis on the inner working of the ECtHR. It is, however, also important to understand the external factors relevant for the functioning of the Strasbourg system. One matter to consider is the collateral damage to the ECtHR's self-regulatory powers by forces outside the Court's mandate. Recent historical events provide a prime example of this. The conflict between the Russian Federation and Ukraine has resulted in sanctions imposed onto the former. As a result, the Russian Federation has ceased to pay its yearly contribution to the budget of the Council of Europe. ${ }^{6}$ Soon after this,

6 Council of Europe. "Secretary General: Russia leaving the Council of Europe would be a "huge setback" for human rights." Newsroom. 11 Oct 2018. Available at https://www.coe.int/en/web/ portal/-/secretary-general-russia-leaving-the-council-of-europe-would-be-a-huge-setbackfor-human-rights accessed on 23 February 2021. 
Turkey threatened to do the same. ${ }^{7}$ Both the Russian Federation and Turkey are important members of the human rights system enforced by the ECtHR, both in terms of the number of applications received from these countries and the number of decisions adopted by the ECtHR against them. Their decision not to contribute to the budget of the Council of Europe weakens the system and, if prolonged or embraced by more member states, will become part of the zeitgeist and could threaten the existence of the whole system.

The same stands true for the relationship between the EU and the ECtHR. The process of accession of the EU to the ECtHR is currently blocked by the advisory opinion of the ECJ with no solution in view. This extended blockage hampers the ECtHR's self-regulatory powers because, first, the ECtHR has no influence over the process and, second, because the blocked accession becomes entrenched with the passage of time, preventing it from taking place.

7 Dermirtas, Serkan. "Turkey aims to exit from CoE monitoring process ASAP." Hurriyet Daily News. 5 Nov 2018. Available at http://www.hurriyetdailynews.com/opinion/serkan-demirtas/ turkey-aims-to-exit-from-coe-monitoring-process-asap-138556 accessed on 23 February 2021. 